\title{
Climatological study of the southwestern region of Saudi Arabia. I. Rainfall analysis
}

\author{
M. A. Abdullah*, M. A. Al-Mazroui \\ Faculty of Meteorology, King Abdul Aziz University, PO Box 9034, Jeddah 21413, Saudi Arabia
}

\begin{abstract}
ABSTRAC'T. The annual rainfall in the southwestern region of Saudi Arabia was analyzed. The study area was divided into regions and subregions depending on the altitude above mean sea level and mean annual rainfall. The classification was supported by comprehensive statistical analysis. The results showed that spring is the main season for rainfall, followed by summer. The gamma distribution was found to provide the best fit, followed by the normal distribution. The analysis of interannual and relative interannual variability showed that regions I and $V$ (adjacent to and furthest away from the coast, respectively, in the southern part of the study area) can be classified as arid, while regions II, III and IV (between and to the north of regions I and V) are classified as semi-arid.
\end{abstract}

KEY WORDS: Saudi Arabia - Asir - Statistical analysis - Rainfall · Annual rainfall distribution - Rainfall variability A Arid and semi-arid regions

\section{INTRODUCTION}

The amount of rainfall received over an area is an important factor in assessing the amount of water available to meet the various demands of agriculture, industry, and other human activities. Therefore, the study of the distribution of rainfall in time and space is very important for the welfare of the national economy.

Many applications of rainfall data are enhanced by a knowledge of the actual distribution of rainfall rather than relying on simple summary statistics. A large number of studies investigating the use of particular distributions to represent the actual rainfall patterns have been employed. Waylen et al. (1996), in a study of spatial variability of annual rainfall in Costa Rica for 100 stations, found that rainfall frequency can be represented by a normal distribution. They used a goodness-of-fit procedure to test the significance of the distribution using the Kolmogorov-Smirnov test. Also, they reported that the normal distribution provides an adequate description of annual rainfall frequency at different sites. Eltahir (1992) found in central and western Sudan, that in cases in which the normal distribution did not adequately describe annual rainfall, the

•E-mail: mef3025@kaau.edu.sa gamma distribution was a possible alternative. Rodhe \& Virji (1976) noted that deviations from normality were common at low-rainfall stations in northern Kenya. Odumodu (1983), in his study of average monthly rainfall amounts for the high plateau in Nigeria, found that these were approximately normally distributed. On this basis, he calculated the probabilities of receiving discrete amount of rainfall in that area. Chow (1954), in his investigation of the lognormal distribution, suggested relationships for calculating the mean and variance without taking the logarithms of all the data. Brakensiek (1958) also discussed a least. squares procedure for estimating the parameters of the lognormal distribution. On the other hand, the gamma distribution has been widely used in climatology and hydrology. Rainfall probabilities for durations of days, weeks, months and years have been documented using the gamma distribution (Haan 1979).

\section{DESCRIPTION AND TOPOGRAPHY OF THE STUDY AREA}

The southwestern region of the Kingdom of Saudi Arabia extends from $16.5^{\circ}$ to $22^{\circ} \mathrm{N}$ and from $40^{\circ}$ to $43.5^{\circ} \mathrm{E}$. The area is bounded by the Red Sea on the 


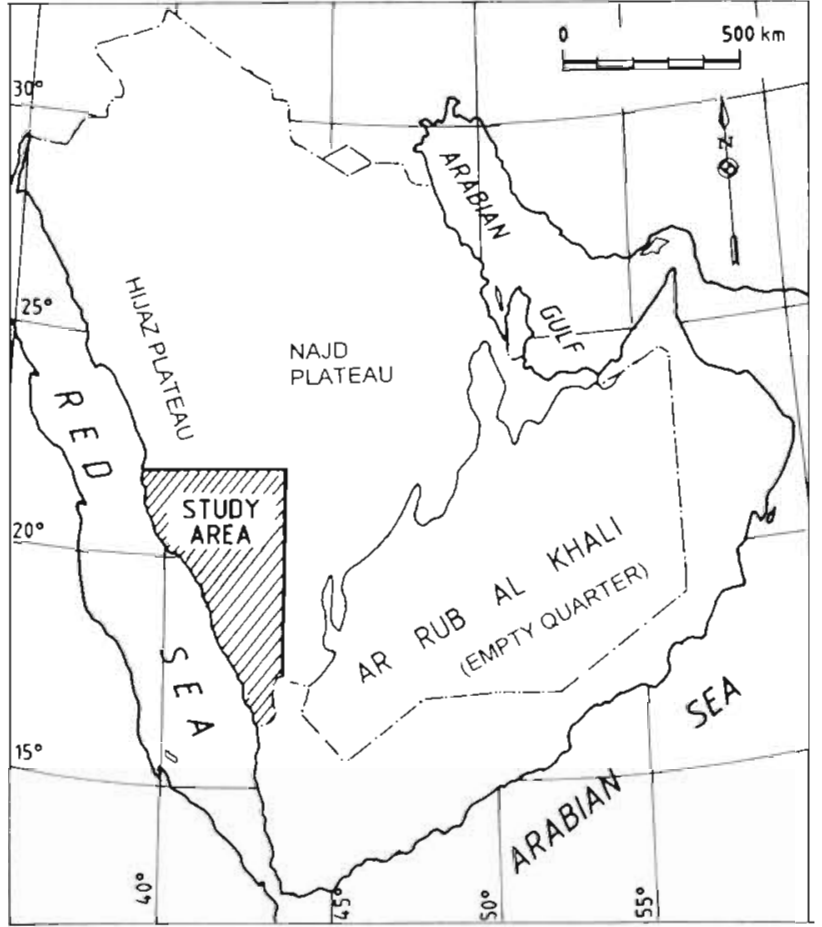

Fig. 1. Saudi Arabia, showing the location of the study area in the southwestern region

west. On the east, the region is bounded by the Najd Plateau and the Empty Quarter. The Hijaz Plateau bounds the region from the north (Fig. 1). The region is delineated by the Asir escarpment which runs parallel to the Red Sea coast, approximately 70 to $100 \mathrm{~km}$ inland. The western slope of the Asir escarpment is very steep. The area to the east of the escarpment is characterized by large catchments with a milder slope (Fig. 2).

\section{SYNOPTIC CLIMATOLOGY OF SAUDI ARABIA}

\subsection{Winter}

In this season, the climate of Saudi Arabia is controlled by the interaction of Siberian high pressure, the Mediterranean lows and the Sudan trough (Fig. 3). The Mediterranean cyclones, which migrate from west to east in association with upper troughs and active phases of subtropical and polar jets, are considered the main rain-producing synoptic systems. Their potential generally decreases from north to south except for the mountainous areas, where uplift motion acts as a regional factor. The ridge of the Siberian high which advects cold and dry air extends into the northeastern regions of Saudi Arabia. The trough of the Sudan low advects warm humid air in the lower atmospheric layer to the southwestern parts of the country. When the cold air which is associated with the Siberian ridge extends especially far into the southern region and the humid air from the Sudan trough is concentrated along the Red Sea, the rainfall that occurs in this case is due to both instability and orography.

\subsection{Summer}

In this season the whole circulation pattern is altered. The middle latitude disturbances of the extratropical type do not affect the area any more. Saudi Arabia's climate is governed by a thermal low which is, in fact, an extension of the Indian monsoon low centered over Asia (Fig. 4). The southern parts of the country are under the influence of the monsoon trough. This trough brings southwesterlies which are conditionally unstable, and their potential for rainfall

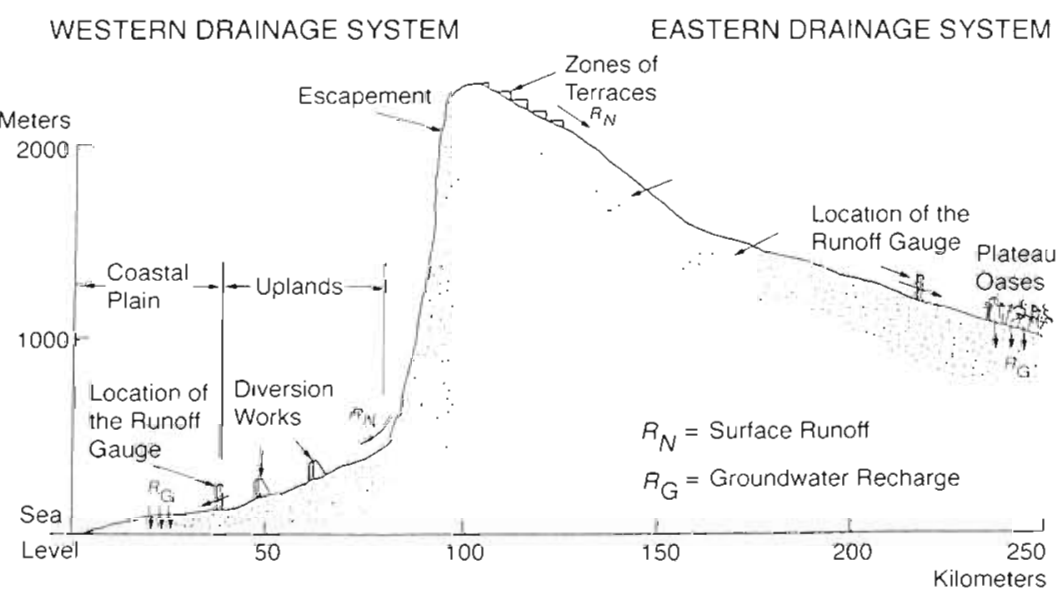

Fig. 2. Topography of the southwestern region (after Abdulrazzak et al. 1995) 


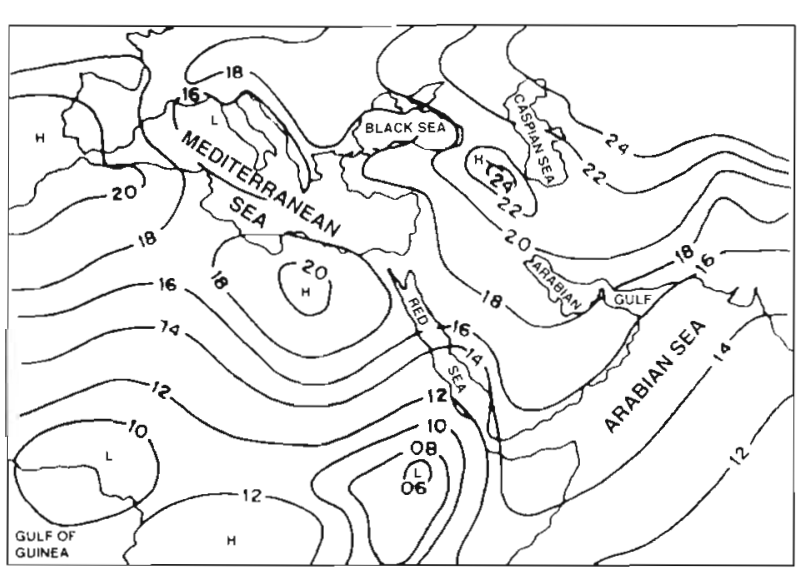

Fig. 3. Distribution of mean sea level pressure in winter

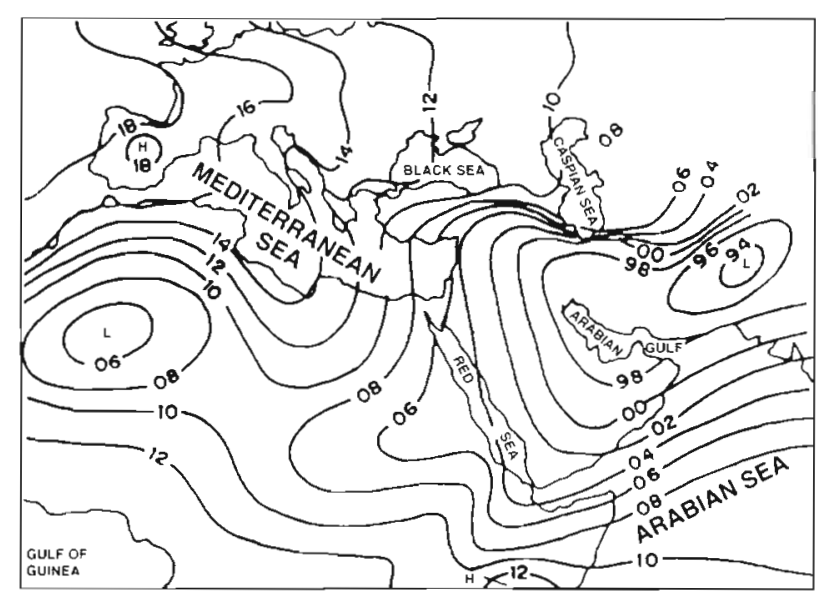

Fig. 4. Distribution of mean sea level pressure in summer

depends on the topography and the nature of the underlying surface (Abdullah et al. 1992). Consequently, the summer rainfall is restricted to the southwestern region. From the subtropical high centered over the Atlantic Ocean, a ridge extends over the northeastern parts of the country and advects cold air. Thus, the northern part of Saudi Arabia is ultimately dry.

According to Köppen, the whole area of the country can be classified as having a hot desert climate. The southwestern region is an exception, where a mild steppe climate prevails. In this region, rain is more frequent in winter and spring than in summer and autumn. The effect of topography on temperature and rainfall is very distinct. Thus the southwestern part of Saudi Arabia is characterized by unique climatic and topographic features. It receives more rain than any other part. The distribution of the winter rainfall shows maximum values in the northern part of the plateau (e.g Nimas) and gradually decreases in the lowlands on the eastern and western sides. Also, low-altitude and coastal stations receive small amounts of rainfall.

\section{METHODOLOGY}

Monthly records of rainfall data for 23 yr (1970 to 1992) were obtained from the Hydrology Division of Ministry of Agriculture and Water (MAW) and Meteorological Environment and Protection Agency (MEPA). The data were collected from 50 stations. Only the complete records from 30 stations have been used in the present study.

A standard analytical procedure is followed for rainfall frequency analysis. This includes selection of an appropriate probability distribution that fits the observed data. Four frequency distribution functions are used, namely, normal, lognormal, exponential and gamma distributions. To compute parameters of a distribution for a particular set of data, the maximum likelihood method is used.

\subsection{Normal distribution}

The normal distribution is generally written as (Haan 1979):

$$
P(X)=\left(2 \pi \sigma^{2}\right)^{-1 / 2} e^{-1 / 2 \frac{(X-\mu)^{2}}{\sigma^{2}}}
$$

where $P(X)$ is the probability density function, and $\mu$ and $\sigma^{2}$ are the mean and variance of the normal distribution. The cumulative standard normal is given by.

where $t=\frac{X-\mu}{\sigma}$

$$
P(Z)=\int_{-\infty}^{Z}(2 \pi)^{-1 / 2} e^{-t^{2} / 2} d t
$$

\subsection{Lognormal distribution}

The lognormal distribution can be written as:

$P(X)=\left(2 \pi X^{2} \sigma_{y}^{2}\right)^{-1 / 2} \exp \left[-\frac{1}{2}\left(\ln X-\mu_{Y}\right)^{2} / \sigma_{Y}^{2}\right] \quad(X>0)$

\subsection{Exponential distribution}

The exponential density function is given by:

$$
P(X)=\lambda \mathrm{e}^{-\lambda X} \quad(X>0, \lambda>0)
$$


and the cumulative exponential distribution by:

$$
P(X)=\int_{0}^{X} \lambda e^{-\lambda t}=1-e^{-\lambda X} \quad(X>0)
$$

The mean and variance of the exponential distribution are $1 / \lambda$ and $1 / \lambda^{2}$.

\subsection{Gamma distribution}

The gamma density function is given by:

$$
P(X)=\lambda^{n} X^{n-1} \mathrm{e}^{-\lambda X / \Gamma(\eta)} \quad(X>0)
$$

Also, the cumulative gamma distribution can be written as:

$$
P(X)=\int_{0}^{X} \lambda^{n} t^{n-1} e^{-\lambda t} / \Gamma(\eta) \mathrm{d} t
$$

where $\Gamma(\eta)$ is the gamma function. $\eta$ is the shape parameter. It can be estimated as $\hat{\eta}$, which is given by:

$$
\hat{\eta}=(1+\sqrt{1+4 y / 3}) / 4 y-\Delta \hat{\eta}
$$

where $y$ is $\ln \bar{X}-\overline{\ln X}$ and $\Delta \dot{\eta}$ is a correction term. $\lambda$ is the scale parameter. It can be estimated as $\hat{\lambda}$ which is given by:

$$
\hat{\lambda}=\frac{\hat{\eta}}{\bar{X}}
$$

The observed rainfall data and those obtained from the previously discussed probability distributions are subjected to a test of goodness-of-fit using the chi-

\begin{tabular}{|c|c|c|c|c|c|}
\hline $\begin{array}{l}\text { Stn } \\
\text { no. }\end{array}$ & Str name & Code & $\begin{array}{l}\text { Eleva- } \\
\text { tion }(\mathrm{m})\end{array}$ & $\begin{array}{l}\text { Long. } \\
\text { (deg) }\end{array}$ & $\begin{array}{l}\text { Lat. } \\
\text { (deg) }\end{array}$ \\
\hline 1 & Gizan & GIZ & 7 & 42.58 & 16.88 \\
\hline 2 & Kiyat & KIY & 30 & 41.40 & 18.73 \\
\hline 3 & Sabya & $\mathrm{SAB}$ & 40 & 42.62 & 17.17 \\
\hline 4 & Mudaylif & MUD & 53 & 41.05 & 19.53 \\
\hline 5 & Malaki & MAL & 190 & 42.95 & 17.05 \\
\hline 6 & Kwash & KWA & 350 & 41.88 & 19.00 \\
\hline 7 & Nimas & NIM & 2600 & 42.15 & 19.10 \\
\hline 8 & Biljuarshy & BIL & 2400 & 41.55 & 19.87 \\
\hline 9 & Abha & $\mathrm{ABH}$ & 2190 & 42.48 & 18.20 \\
\hline 10 & Mindak & MIN & 2400 & 41.33 & 20.10 \\
\hline 11 & Ibalah & IBA & 2480 & 42.25 & 18.68 \\
\hline 12 & Thulth Bani Amer & THU & 2000 & 41.98 & 19.47 \\
\hline 13 & Tenomah & TEN & 2100 & 42.17 & 18.92 \\
\hline 14 & Alaya & ALA & 1850 & 41.90 & 19.53 \\
\hline 15 & Sir Lasan & SIR & 2100 & 42.60 & 1.8 .25 \\
\hline 16 & Ademah & ADE & 1715 & 41.93 & 19.75 \\
\hline 17 & Khamis & $\mathrm{KHA}$ & 2056 & 42.80 & 18.30 \\
\hline 18 & Tajer & TAJ & 2300 & 42.38 & 18.52 \\
\hline 19 & Shafa escarpment & SHE & 2190 & 40.30 & 21.08 \\
\hline 20 & Shafa Bani Sofian & SBS & 2130 & 40.32 & 21.12 \\
\hline 21 & Mid escarpment & MIDE & 910 & 40.22 & 21.35 \\
\hline 22 & Wadi Daygah & WDAY & 540 & 40.12 & 21.22 \\
\hline 23 & Hema Saysid & HEM & 1497 & 40.50 & $2 t .30$ \\
\hline 24 & Taif & TAIF & 1530 & 40.45 & 21.40 \\
\hline 25 & Sayl Al-Kabir & SAY & 1230 & 40.42 & 21.62 \\
\hline 26 & Turabah & TUR & 1130 & 41.67 & 21.18 \\
\hline 27 & Wadi Turabah & WTUR & 1310 & 41.37 & 20.82 \\
\hline 28 & Samakh & SAM & 1480 & 42.80 & 19.33 \\
\hline 29 & Heifah & HEIF & 1090 & 42.53 & 19.87 \\
\hline 30 & Bishah & BSH & 1020 & 42.60 & 20.02 \\
\hline
\end{tabular}
squared test.

In this study, SAS and SPSS statistical packages were used to analyze the data. The contour maps were
Table 1. Names and locations of the stations in the study area

plotted by SURFER version 6.0.4. This uses the Kriging method for the grid points.

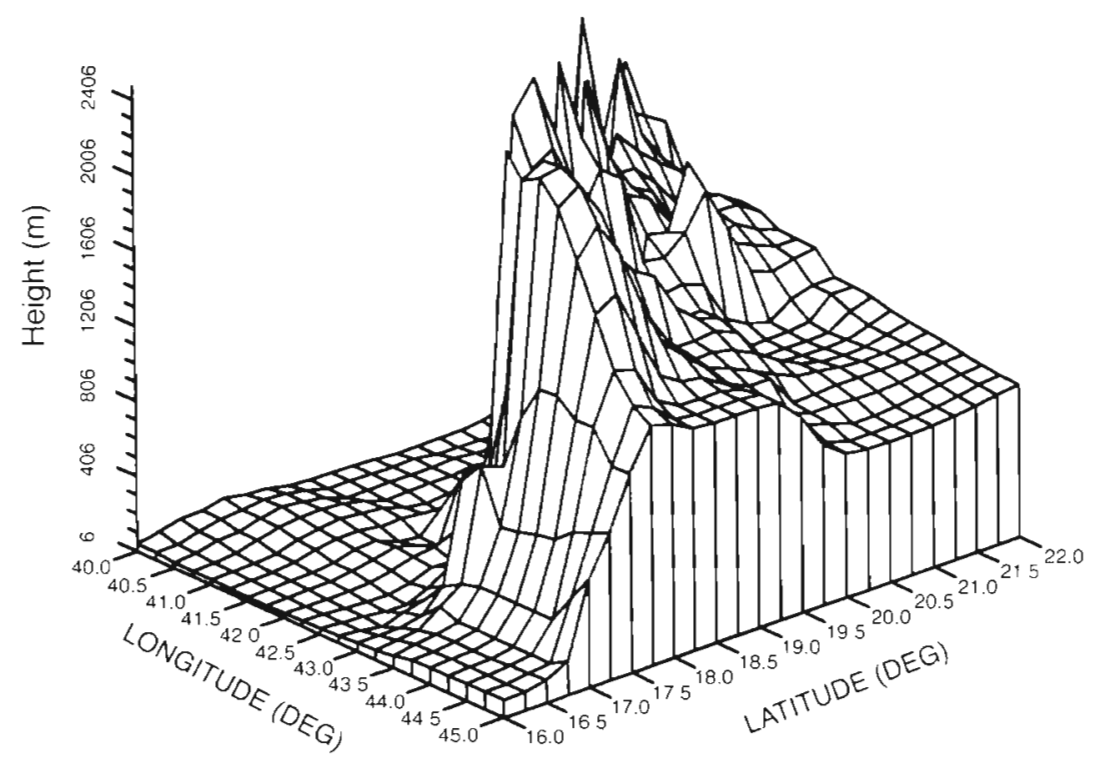

Fig. 5. Three-dimensional orography diagram of the study area 


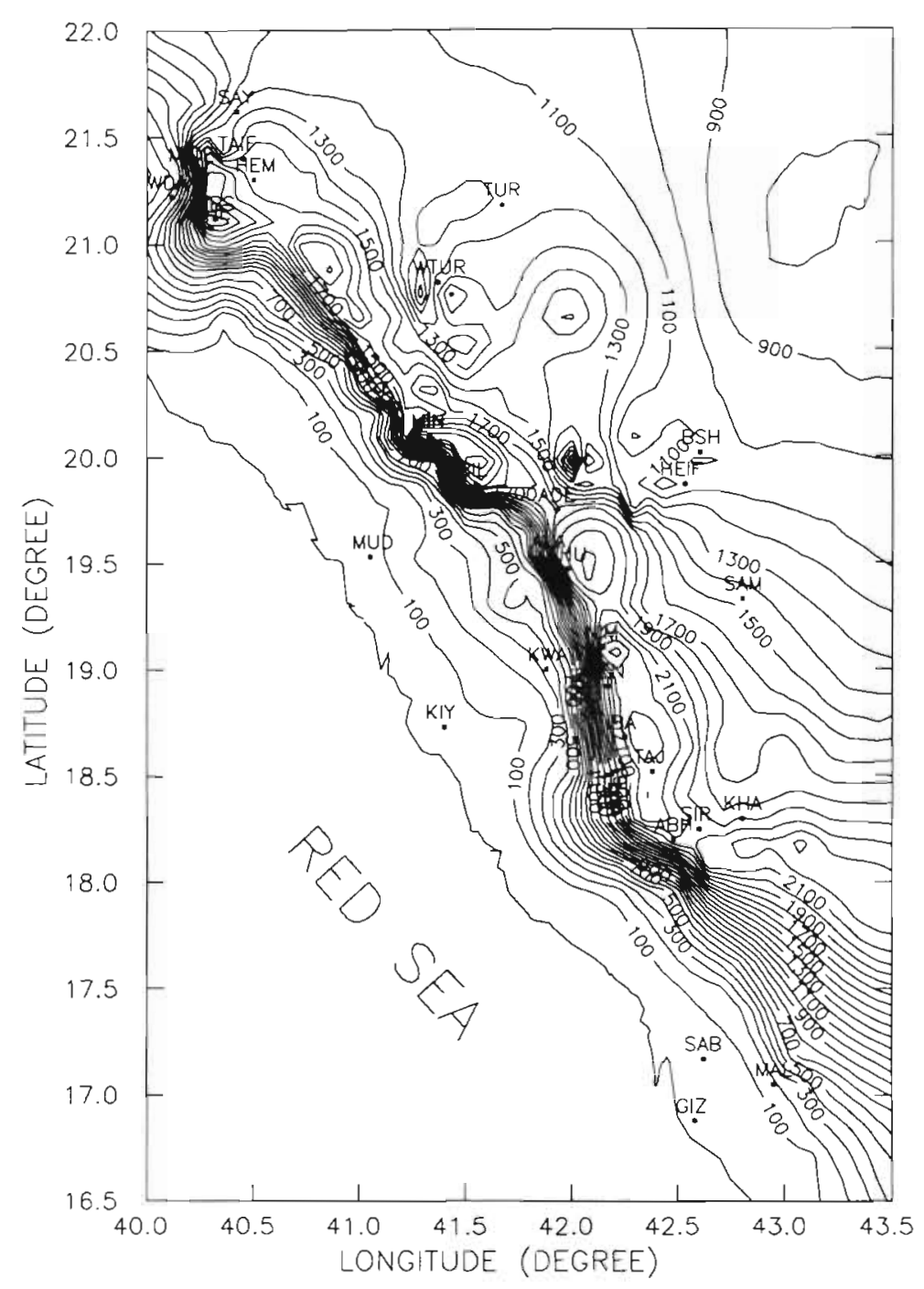

Fig. 6. Contour map (100 m intervals) of the study area gests that it can be divided into 5 regions (Fig. 7). It may be noticed that both regions III and IV have a wide range of annual rainfall between stations. Accordingly, each of these regions may be divided into subregions depending on mean annual rainfall and its variation. Analysis of variance (ANOVA) was performed using 2 tests, namely least significant difference (LSD) and Duncan's new multiple range (Steel \& Torrie 1980, Damon \& Harvey 1987). These classify the stations into groups according to the significance level of the variation of the means. A statistical package (SAS) was used for this purpose. A $10 \%$ level of significance for variation between the means was taken as a base for regionalization. Prior to using ANOVA, assumptions of normality and homogeneity of variances in each region were investigated. It was found that all the stations fit the normal distribution adequately (see Table 5). The Bartlett test (Steel \& Torrie 1980) was used to check the homogeneity of variances. The analysis shows that regions I and II are homogeneous at the $5 \%$ level of significance using the observed data. Square root and logarithmic transformations failed to meet the homogeneity requirements for region III. This is probably due to the nature of the orography of this region (Fig. 5). As this region is one of the important agricultural regions in the area of the study, further investigation was performed to identify the stations which caused nonhomogeneity. Excluding Khamis and Tajer, due to their locality, the test showed homogeneity at the $5 \%$ level of significance.

\section{RESULTS AND DISCUSSION}

\subsection{Classification of the study area into regions and subregions}

The altitude of the 30 stations representing the area ranges from mean sea level up to $2600 \mathrm{~m}$ (Table 1). A 3 -dimensional diagram for the orography of the southwestern region is shown in Fig. 5. The region appears as a cliff toward the Red Sea, then the escarpment gradually slopes eastward. The figure also shows distinctive elevations at the top of the escarpment. A contour map of the study area is shown in Fig. 6. The large gradient on the map is an indication of how steep the cliff is.

A preliminary classification based on the topography of the area and the elevation of the stations sug-
In this study, it was decided to use data of all the stations in region III. In further studies, the previously mentioned 2 stations may be dealt with separately. Both the observed and transformed data were tested and showed the same results concerning the subdivisions of the regions. Figs. $8 \& 9$ show regions III and IV with their subregions.

\subsection{Mean annual rainfall distribution of the study area}

Annual rainfall is probably the most important simple climatic indicator of productivity. Fig. 10 shows the mean annual rainfall for the area of the study. The maximum mean annual rainfall appears on region III specifically at Nimas (512 mm), Biljurashy $(430 \mathrm{~mm})$ 


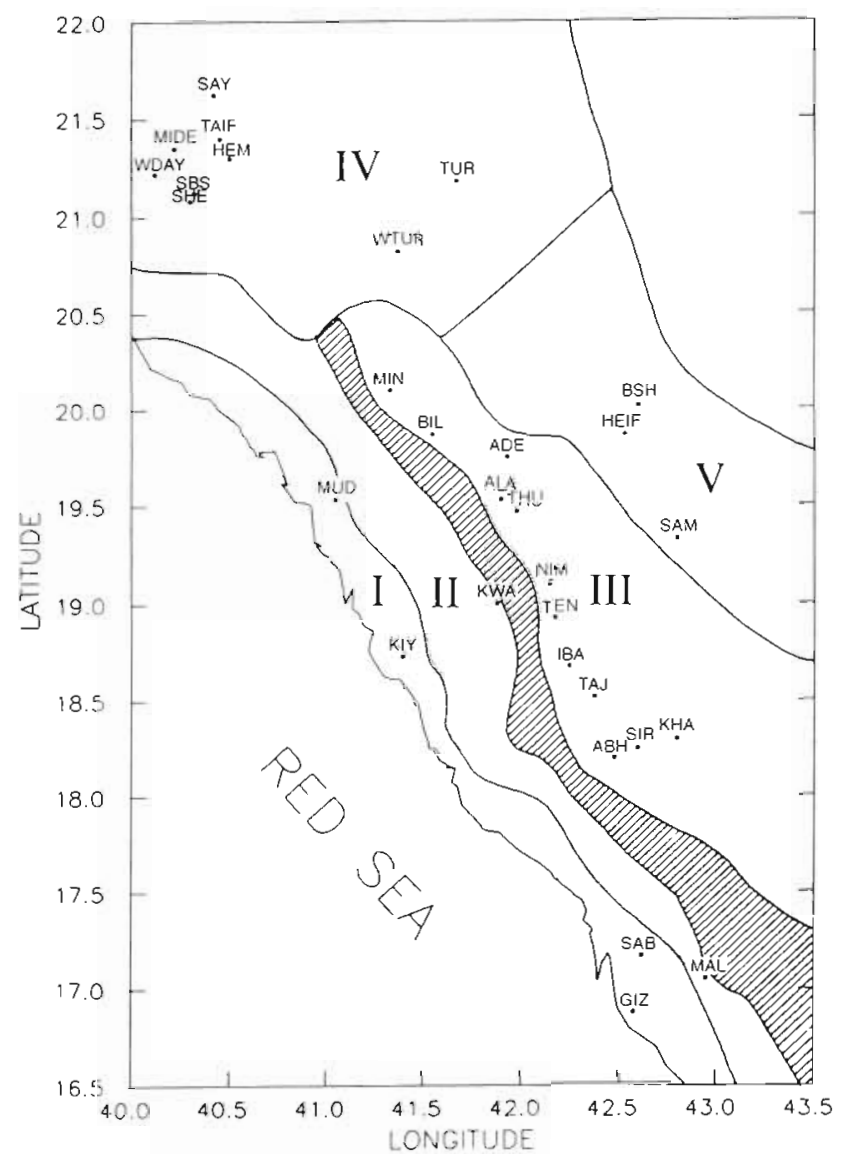

Fig. 7. The 5 climatic regions in the southwestern part of Saudi Arabia, classified according to height above mean sea level

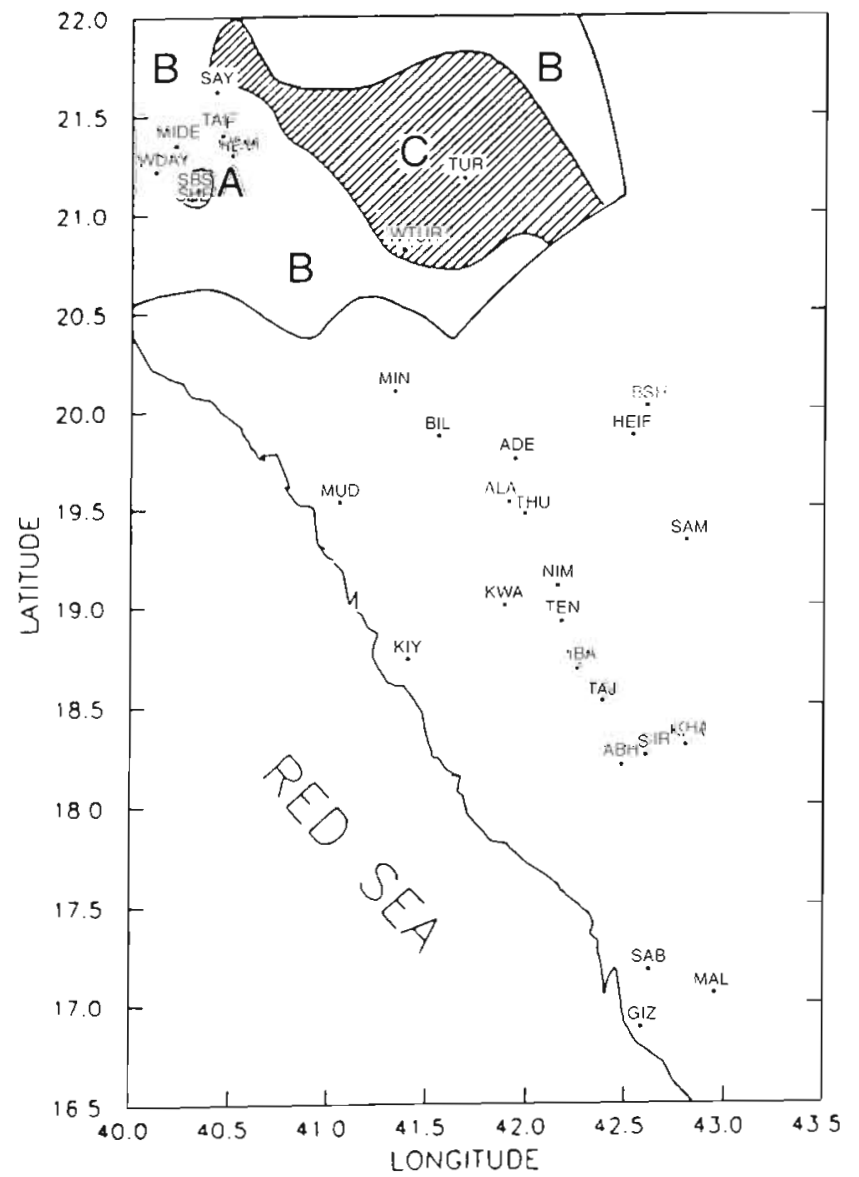

Fig. 9. Region IV of the study area, classified into 3 subregions dccording to mean annual rainfall distribution

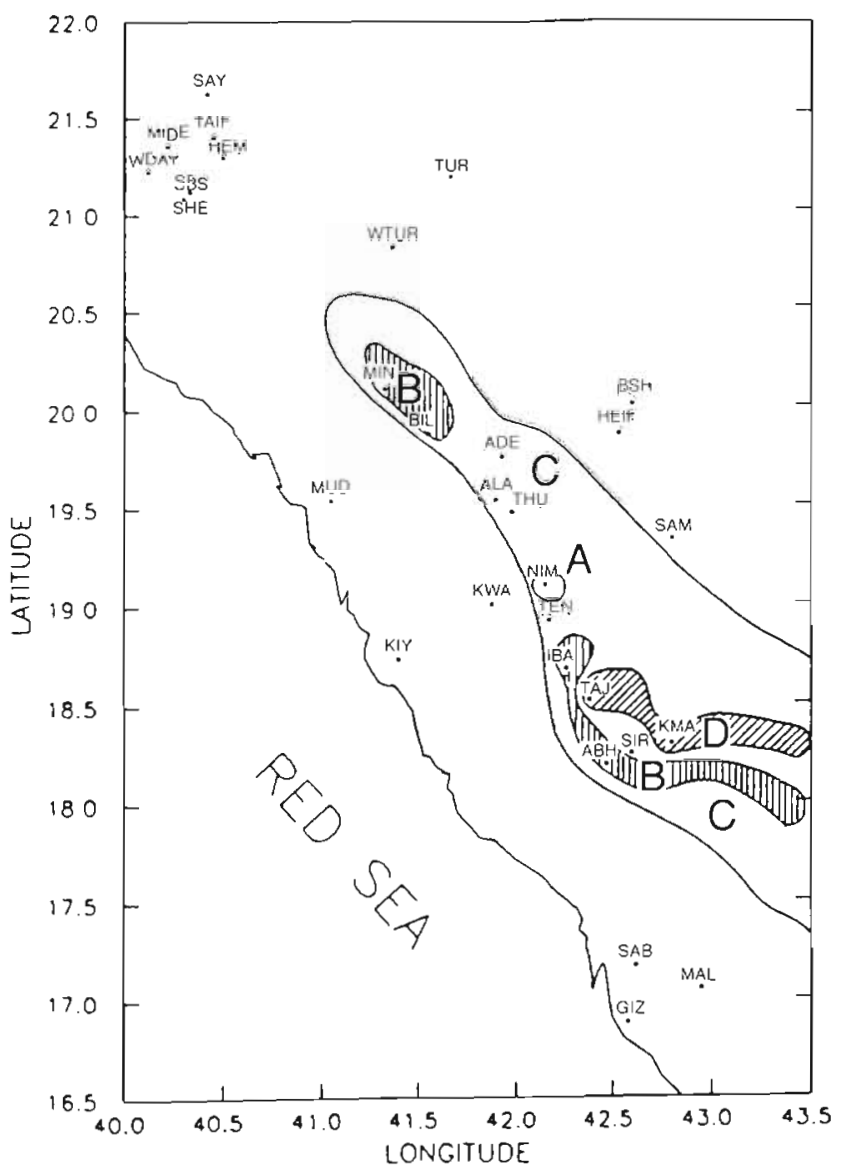

Fig. 8. Region III of the study area, classified into 4 subregions according to mean annual rainfall distribution

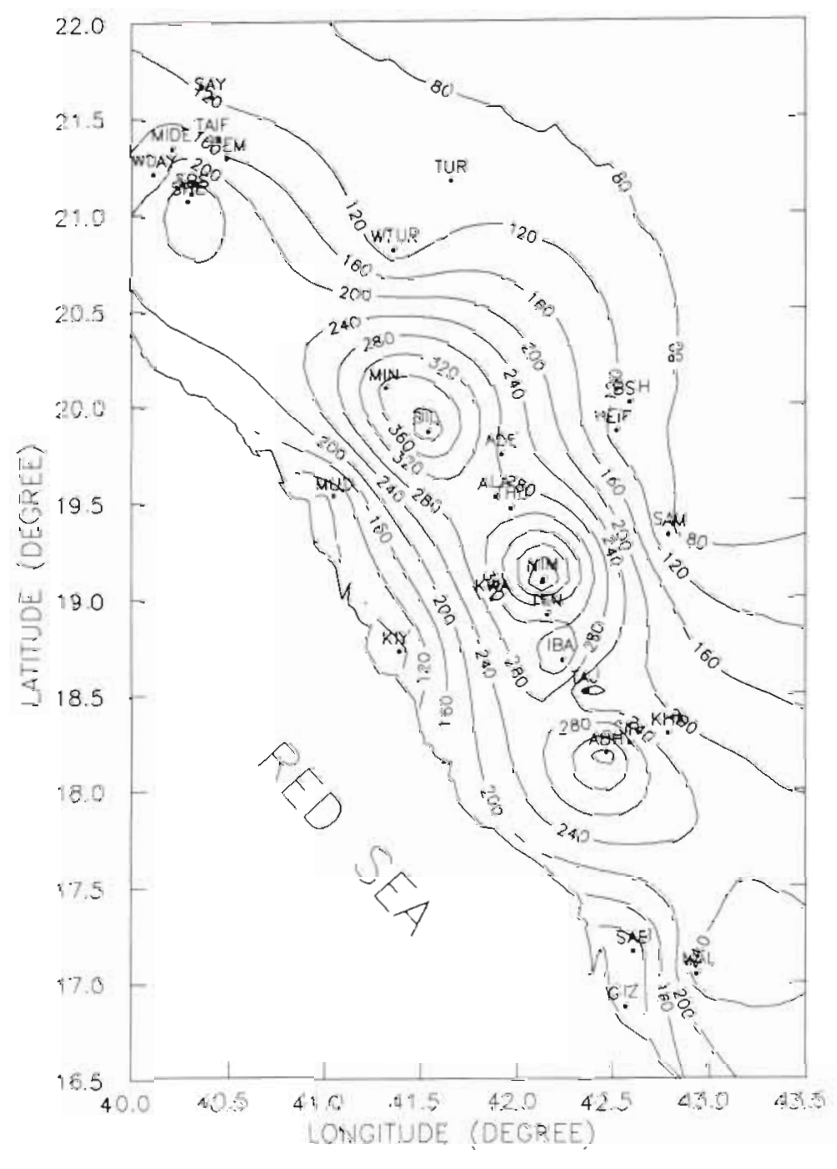

Fig. 10. Mean annual rainfall ( $\mathrm{mm})$ in the study area 
Table 2. Statistical analysis of annual rainfall in the study area. CV: coefficient of variation

\begin{tabular}{|c|c|c|c|c|c|c|c|}
\hline Region & Station & Mean & SD & $\mathrm{CV}$ & Skewness & Min. & Max. \\
\hline \multirow[t]{4}{*}{1} & Gizan & 83.90 & 70.96 & 0.85 & 1.40 & 5.25 & 294.30 \\
\hline & Kiyat & 62.88 & 67.61 & 1.08 & 1.94 & 0.40 & 293.00 \\
\hline & Sabya & 92.25 & 40.61 & 0.44 & -0.33 & 6.50 & 158.00 \\
\hline & Mudaylif & 75.11 & 54.03 & 0.72 & 0.68 & 7.40 & 197.40 \\
\hline \multirow[t]{2}{*}{ II } & Malaki & 267.63 & 134.87 & 0.50 & 0.22 & 84.70 & 508.20 \\
\hline & Kwash & 301.66 & 149.77 & 0.50 & 0.55 & 75.60 & 656.20 \\
\hline III A & Nimas & 512.71 & 174.37 & 0.34 & 0.17 & 208.41 & 853.00 \\
\hline \multirow[t]{4}{*}{ III $\mathrm{B}$} & Biljuarshy & 430.71 & 216.63 & 0.50 & 1.36 & 167.40 & 985.60 \\
\hline & Abha & 394.21 & 114.08 & 0.29 & -0.09 & 129.90 & 590.10 \\
\hline & Mindak & 379.77 & 168.07 & 0.44 & 0.51 & 110.10 & 769.50 \\
\hline & Ibalah & 371.71 & 145.52 & 0.39 & 0.37 & 53.60 & 727.60 \\
\hline \multirow[t]{5}{*}{$111 \mathrm{C}$} & Thulth Bani Amer & 299.09 & 135.36 & 0.45 & -0.11 & 66.40 & 521.00 \\
\hline & Tenomah & 295.40 & 142.49 & 0.48 & -0.32 & 25.20 & 536.60 \\
\hline & Alaya & 289.69 & 170.39 & 0.59 & 0.94 & 12.20 & 790.40 \\
\hline & Sir Lasan & 281.05 & 104.04 & 0.37 & 0.25 & 87.60 & 488.50 \\
\hline & Ademah & 267.65 & 170.70 & 0.64 & 1.12 & 13.40 & 774.90 \\
\hline \multirow[t]{2}{*}{ III D } & Khamis & 209.23 & 67.26 & 0.32 & 0.42 & 82.20 & 369.50 \\
\hline & Tajer & 172.26 & 93.54 & 0.54 & 0.45 & 23.00 & 380.00 \\
\hline \multirow[t]{2}{*}{ IV A } & Shafa escarpment & 282.09 & 111.48 & 0.40 & 0.26 & 0.00 & 542.00 \\
\hline & Shafa Bani Sofian & 273.88 & 124.32 & 0.45 & 0.02 & 0.90 & 510.00 \\
\hline \multirow[t]{4}{*}{ IV B } & Mid escarpment & 193.25 & 86.16 & 0.45 & 0.41 & 0.20 & 403.80 \\
\hline & Wadi Daygah & 168.90 & 87.84 & 0.52 & 0.35 & 0.60 & 329.30 \\
\hline & Hema Saysid & 158.88 & 61.39 & 0.39 & 0.70 & 0.80 & 293.30 \\
\hline & Taif & 151.80 & 76.89 & 0.51 & 0.89 & 0.00 & 339.40 \\
\hline \multirow[t]{3}{*}{ IV C } & Sayl Al-Kabir & 114.31 & 63.30 & 0.55 & 1.45 & 0.20 & 312.40 \\
\hline & Turabah & 101.00 & 49.82 & 0.49 & 0.26 & 0.20 & 198.50 \\
\hline & Wadi Turabah & 96.23 & 46.66 & 0.48 & 1.68 & 0.80 & 253.80 \\
\hline \multirow[t]{3}{*}{$\mathrm{V}$} & Samakh & 77.55 & 48.32 & 0.62 & 0.43 & 7.20 & 170.50 \\
\hline & Heifah & 99.54 & 78.40 & 0.79 & 1.43 & 9.30 & 327.20 \\
\hline & Bishah & 107.53 & 88.85 & 0.83 & 2.85 & 23.20 & 453.00 \\
\hline
\end{tabular}

and Abha (324 mm). Rainfall occasionally reaches as much as $900 \mathrm{~mm}$ (Biljurashy) (Table 2).

The rainfall distribution is affected by the Asir mountains, which run from the northwest to the southwest. Mean annual rainfall of the area near the sea is less than $120 \mathrm{~mm}$. The increase in elevation from sea level to $350 \mathrm{~m}$ (Kwash, region II) has a marked influence on rainfall, reaching an annual value of about $300 \mathrm{~mm}$. Moreover, the mean annual rainfall of Malaki (elevation $190 \mathrm{~m}$ ) is about $268 \mathrm{~mm}$. The eastern side of the escarpment (region IV) receives less rainfall than the western side. The latter steeply rises and enhances the air circulation of the westerly and northwesterly winds that carry moisture from the Red Sea. There is no significant contribution to precipitation from the eastern slopes, which receive annual rainfall ranging from 100 to $200 \mathrm{~mm}$.

\subsection{Annual rainfall variability}

The ecology of any region is not only dependent on how much rainfall falls but also on how it varies from year to year. The extent of variability is expressed by the size of the departures from the mean, of which the standard deviation is a measure. The standard deviation divided by the mean yields a coefficient of variability. This makes it possible to compare the variability of rainfall in places with different mean annual rainfall. The coefficient of variability was calculated for the area of the study. Its spatial distribution is seen in Fig. 11. As it is generally the case, variability increases with decreasing rainfall. On both sides of the escarpment, the variability coefficient is high. Kiyat (region I) on the western side of the escarpment near the sea, has a maximum variability of 1.08 associated with minimum mean annual rainfall of $62 \mathrm{~mm}$. Similarly, both Heifah and Bishah (region V) show a high annual variability of 0.79 and 0.83 respectively. The mean annual rainfall is about $100 \mathrm{~mm}$ for Heifah and about $108 \mathrm{~mm}$ for Bishah. By contrast, stations on the plateau show less variability. The maximum annual variability of 0.64 is shown at Alaya, while the minimum of 0.29 is calculated in Abha. The mean annual rainfall is about 290 and $390 \mathrm{~mm}$ for the 2 stations respectively. 


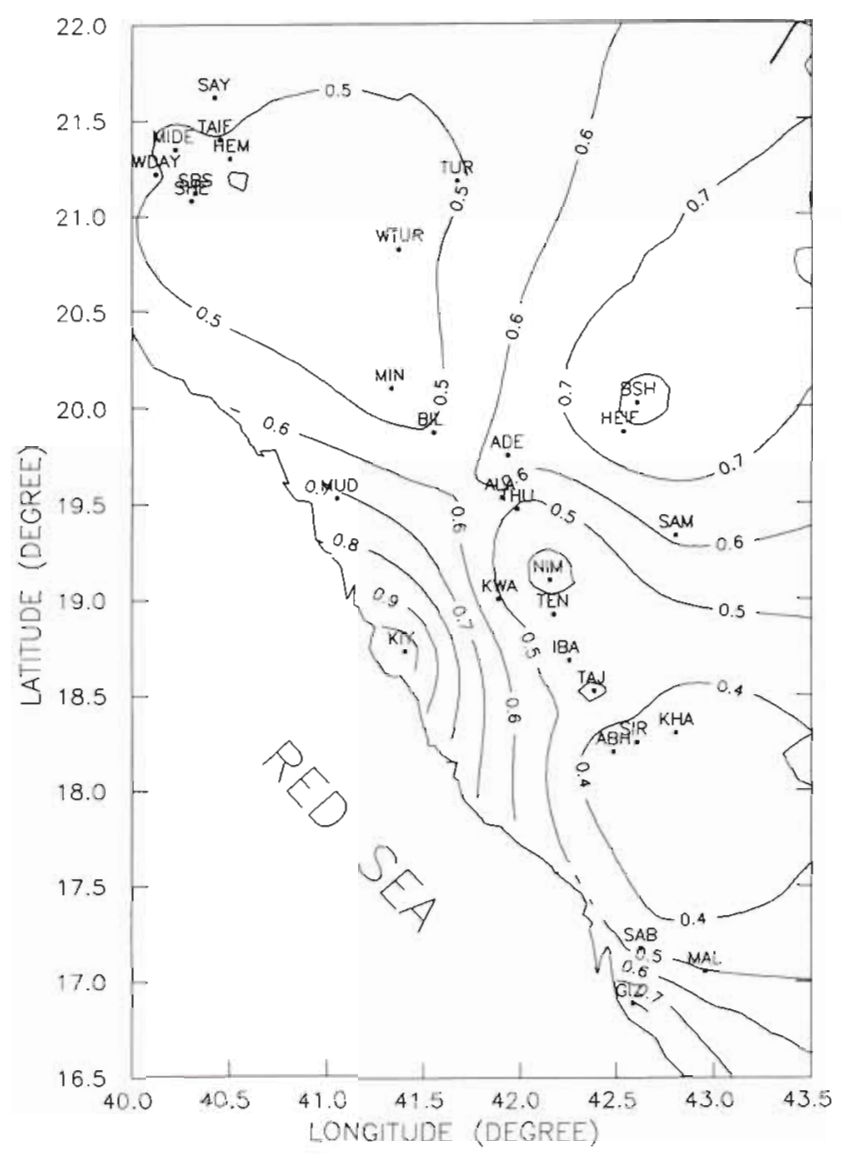

Fig. 11. Coefficient of variability of annual rainfall

One of the distinctive features of precipitation in arid and semi-arid areas is its great variability. The interannual variability $\left[I_{a v}\right]$ is used to give a broad, overall picture of various climatic factors which cause unreliable rainfall. It is a measure of aridity of a region and is calculated by the formula:

$$
\left[I_{c V}\right]=\frac{\sum_{i=2}^{n}\left|\mathrm{P}_{r-1}-\mathrm{P}_{r}\right|}{n-1}
$$

where $\mathrm{P}=$ annual rainfall $i n=$ number of years of observations.

The relative interannual variability $\left[I_{d v}\right]_{\text {rel }}$ is expressed as a percent of the annual average:

$$
\left[I_{a v}\right]_{\mathrm{rel}}=\frac{\left[I_{a v}\right]}{\overline{\mathrm{P}}} \times 100
$$

where $\overline{\mathrm{P}}=$ annual average rainfall.

Table 3 shows $\left[I_{d v}\right]$ and $\left[I_{a r}\right]_{\text {rel }}$ as related to mean annual rainfall. Regions II and III have low $\left[I_{d v}\right]_{\text {reli }}$ they are classified as semi-arid regions (Brichambaut \& Wallen 1963). Region IV falls between semi-arid and
Table 3 . Interannual $\left[I_{a v}\right]$ variability and relative interannual variability $\left[I_{d v}\right]_{\mathrm{rel}}$ as related to mean annual rainfall in the

\begin{tabular}{|c|c|c|c|c|}
\hline Region & Station & Mean & {$\left[I_{a v}\right]$} & {$\left[I_{a v}\right]_{\text {rel }}$} \\
\hline \multirow[t]{4}{*}{ I } & Gizan & 83.90 & 75.04 & 89.44 \\
\hline & Kiyat & 62.88 & 45.19 & 71.87 \\
\hline & Sabya & 92.25 & 38.96 & 42.24 \\
\hline & Mudaylif & 75.11 & 65.22 & 86.83 \\
\hline \multirow[t]{2}{*}{ II } & Malaki & 267.63 & 119.58 & 44.68 \\
\hline & Kwash & 301.66 & 153.08 & 50.75 \\
\hline III A & Nimas & 512.71 & 182.44 & 35.58 \\
\hline \multirow[t]{4}{*}{ III B } & Biljuarshy & 430.71 & 248.04 & 57.59 \\
\hline & Abha & 394.21 & 126.07 & 31.98 \\
\hline & Mindak & 379.77 & 154.55 & 40.70 \\
\hline & Ibalah & 371.71 & 154.56 & 41.58 \\
\hline \multirow[t]{5}{*}{ III C } & Thulth Bani Amer & 299.09 & 95.82 & 32.04 \\
\hline & Tenomah & 295.40 & 136.01 & 46.04 \\
\hline & Alaya & 289.69 & 154.35 & 53.28 \\
\hline & Sir Lasan & 281.05 & 105.92 & 37.69 \\
\hline & Ademah & 267.65 & 178.20 & 66.58 \\
\hline \multirow[t]{2}{*}{ III $D$} & Khamis & 209.23 & 79.38 & 37.94 \\
\hline & Tajer & 172.26 & 83.32 & 48.37 \\
\hline \multirow[t]{2}{*}{ IV A } & Shafa escarpment & 282.09 & 114.95 & 40.75 \\
\hline & Shafa Bani Sofian & 273.88 & 134.74 & 49.19 \\
\hline \multirow[t]{4}{*}{ IV B } & Mid escarpment & 193.25 & 96.61 & 49.99 \\
\hline & Wadi Daygah & 1.68 .90 & 92.95 & 55.04 \\
\hline & Hema Saysid & 1.58 .88 & 64.62 & 40.67 \\
\hline & Taif & 151.80 & 85.20 & 56.12 \\
\hline \multirow[t]{3}{*}{ IV C } & Sayl Al-Kabir & 114.31 & 67.47 & 59.02 \\
\hline & Turabah & 101.00 & 56.30 & 55.14 \\
\hline & Wadi Turabah & 96.23 & 45.85 & 47.65 \\
\hline \multirow[t]{3}{*}{ V } & Samakh & 77.55 & 39.57 & 51.03 \\
\hline & Heifah & 99.54 & 80.49 & 80.86 \\
\hline & Bishah & 107.53 & 86.06 & 80.04 \\
\hline
\end{tabular}
study area

arid. The average $\left[I_{\partial v}\right]_{\text {rel }}$ in regions $I$ and $V$ is about $80 \%$; they are arid regions. Gizan in region I shows the highest $\left[I_{d v}\right]_{\text {rel }}$.

\subsection{Estimation of rainfall from different distributions}

For each station in the study area, the appropriate parameters for each type of theoretical distribution, namely normal, exponential, gamma, and lognormal, were calculated using the maximum likelihood method. A summary of these parameters is given in Table 4. These parameters were used to generate expected frequency distributions of annual rainfall. The expected and actual annual rainfall were then subjected to a chi-squared test of goodness-of-fit in order to judge whether or not the assumed distribution adequately described the observed data. Table 5 shows the calculated chi-squared values for all stations in the 5 regions of the study area. The gamma distribution showed the best fit for region I and II. For 
Table 4. Parameters of probability distributions of annual rainfall in the study area

\begin{tabular}{|c|c|c|c|c|c|c|c|c|}
\hline \multirow[t]{2}{*}{ Region } & \multirow[t]{2}{*}{ Station } & \multicolumn{2}{|c|}{ Normal } & \multirow{2}{*}{$\begin{array}{c}\text { Exponential } \\
\lambda\end{array}$} & \multicolumn{2}{|c|}{ Gamma } & \multicolumn{2}{|c|}{ Lognormal } \\
\hline & & Mean & Variance & & Shape & Scale & Mean & Variance \\
\hline \multirow[t]{4}{*}{ I } & Gizan & 83.90 & 5035.99 & 0.0119183 & 1.2174 & 0.0145 & 4.03 & 1.03 \\
\hline & Kiyat & 62.88 & 4571.76 & 0.0159026 & 0.7396 & 0.0118 & 3.44 & 2.24 \\
\hline & Sabya & 92.25 & 1649.53 & 0.0108398 & 2.8352 & 0.0307 & 4.36 & 0.50 \\
\hline & Mudaylif & 75.11 & 2918.92 & 0.0133000 & 1.4958 & 0.0199 & 4.00 & 0.81 \\
\hline \multirow[t]{2}{*}{ II } & Malaki & 267.63 & 18189.96 & 0.0037000 & 3.2197 & 0.0120 & 5.45 & 0.32 \\
\hline & Kwash & 301.66 & 22432.04 & 0.0033150 & 3.4263 & 0.0114 & 5.58 & 0.30 \\
\hline Ill $\mathrm{A}$ & Nimas & 512.71 & 30405.26 & 0.0019504 & 7.2606 & 0.0142 & 6.18 & 0.14 \\
\hline \multirow[t]{4}{*}{$111 \mathrm{~B}$} & Biljuarshy & 430.71 & 46927.38 & 0.0023217 & 4.1855 & 0.0097 & 5.96 & 0.22 \\
\hline & Abha & 394.21 & 13013.69 & 0.0025367 & 9.2677 & 0.0235 & 5.93 & 0.11 \\
\hline & Mindak & 379.77 & 28248.09 & 0.0026332 & 4.1996 & 0.0111 & 5.83 & 0.25 \\
\hline & Ibalah & 371.71 & 21176.51 & 0.0026902 & 4.5535 & 0.0123 & 5.82 & 0.27 \\
\hline \multirow[t]{5}{*}{ III C } & Thulth Bani Amer & 299.09 & 18323.26 & 0.0033435 & 3.4239 & 0.0114 & 5.57 & 0.33 \\
\hline & Tenomah & 295.40 & 20304.17 & 0.0033852 & 2.4594 & 0.0083 & 5.50 & 0.55 \\
\hline & Alaya & 289.69 & 29031.96 & 0.0034520 & 1.8591 & 0.0064 & 5.42 & 0.80 \\
\hline & Sir Lasan & 281.05 & 10823.46 & 0.0035580 & 5.9586 & 0.0212 & 5.56 & 0.17 \\
\hline & Ademah & 267.65 & 29139.30 & 0.0037362 & 1.8184 & 0.0068 & 5.33 & 0.75 \\
\hline \multirow[t]{2}{*}{ III D } & Khamis & 209.23 & 4524.03 & 0.0047793 & 8.2572 & 0.0395 & 5.29 & 0.12 \\
\hline & Tajer & 172.27 & 8748.80 & 0.0058053 & 2.4257 & 0.0141 & 4.96 & 0.50 \\
\hline \multirow[t]{2}{*}{ IV A } & Shafa escarpment & 282.09 & 12427.37 & 0.0035449 & 5.1456 & 0.0182 & 5.56 & 0.20 \\
\hline & Shafa Bani Sofian & 273.88 & 15455.32 & 0.0036512 & 3.6043 & 0.0132 & 5.49 & 0.30 \\
\hline \multirow[t]{4}{*}{ IV B } & Mid escarpment & 193.25 & 7424.38 & 0.0051747 & 3.2144 & 0.0166 & 5.12 & 0.42 \\
\hline & Wadi Daygah & 168.90 & 7715.91 & 0.0059208 & 3.0180 & 0.0179 & 4.98 & 0.35 \\
\hline & Hema Saysid & 158.88 & 3769.22 & 0.0062941 & 6.1678 & 0.0388 & 5.00 & 0.15 \\
\hline & Taif & 151.80 & 5912.02 & 0.0065874 & 3.7226 & 0.0245 & 4.90 & 0.26 \\
\hline \multirow[t]{3}{*}{ IV C } & Sayl Al-Kabir & 114.31 & 4007.46 & 0.0087479 & 3.0524 & 0.0267 & 4.59 & 0.35 \\
\hline & Turabah & 101.00 & 2481.72 & 0.0099009 & 3.0540 & 0.0302 & 4.47 & 0.37 \\
\hline & Wadi Turabah & 96.23 & 2176.92 & 0.0103913 & 4.3693 & 0.0454 & 4.46 & 0.22 \\
\hline \multirow[t]{3}{*}{ V } & Samakh & 77.55 & 2335.10 & 0.0128945 & 1.7217 & 0.0222 & 4.08 & 0.77 \\
\hline & Heifah & 99.54 & 6147.14 & 0.0100463 & 1.4496 & 0.0146 & 4.27 & 0.83 \\
\hline & Bishah & 107.53 & 7894.36 & 0.0093001 & 2.0570 & 0.0191 & 4.45 & 0.44 \\
\hline
\end{tabular}

region III the best fit was found for the normal distribution, followed by the gamma distribution. For region IV, both gamma and normal distributions adequately fit the observed data. In region $V$, gamma and lognormal showed suitable fits for this region. The exponential distribution showed an unacceptable fit in regions II, III, IV and V.

In arid areas, the chi-squared test showed some limitations, especially when rainfall records were relatively short. For example, at some stations of regions I and $V$ (Table 5), the test did not distinguish between normal and exponential distributions. These areas are classified as arid regions in the study area (Table 3 ).

\subsection{Rainfall probability over the study area}

Fig $12 a$ shows the probability that rainfall exceeds $100 \mathrm{~mm}$ using the gamma distribution. In regions II, III and IV the probability is above $80 \%$, reaching above $90 \%$ at the top of the escarpment. In regions I and V the probability is less than $50 \%$. Nearly the same varying probabilities are obtained for annual rainfall amounts of 200 to $600 \mathrm{~mm}$. For region III, as the rainfall amounts increase, the probabilities decrease from $80 \%$ to $10 \%$. Fig. $12 \mathrm{~b}$ was obtained using the normal distribution. No significant differences were observed. The return period, a measure of frequency of occurrence of certain amounts of rainfall, was calculated for region III. For $200 \mathrm{~mm}$, the return period was found to be $15 \mathrm{mo}$, increasing to $10 \mathrm{yr}$ for $600 \mathrm{~mm}$.

\section{CONCLUSIONS}

It was possible from the available data to classify the southwestern part of Saudi Arabia into 5 regions according to the altitude above mean sea level and the mean annual rainfall. The statistical analysis assisted in determining the significance of this classification.

Due to insufficient data records and the aridity of some areas, the correlations between the stations in some regions or subregions showed non-significance in some cases. In this case, the regionalization of stations into groups by LSD and Duncan tests proved that they are useful tools. 
Table 5. Calculated chi-squared values of probability distributions of annual rainfall

\begin{tabular}{|c|c|c|c|c|c|}
\hline Region & Station & Normal ${ }^{+}$ & Exponential ${ }^{\mathrm{b}}$ & Gamma $^{d}$ & Lognormal \\
\hline \multirow[t]{4}{*}{1} & Gizan & 2.40 & 2.29 & 1.55 & 3.34 \\
\hline & Kiyat & 6.42 & 5.28 & 4.84 & 8.45 \\
\hline & Sabya & 6.89 & 12.46 & 4.14 & 4.94 \\
\hline & Mudaylif & 3.01 & 1.86 & 1.57 & 3.24 \\
\hline \multirow[t]{2}{*}{ II } & Malaki & 6.92 & 17.19 & 7.72 & 9.67 \\
\hline & Kwash & 8.92 & 19.24 & 5.76 & 6.41 \\
\hline III A & Nimas & 2.57 & 31.73 & 3.70 & 4.77 \\
\hline \multirow[t]{4}{*}{ III $\mathrm{B}$} & Biljuarshy & 5.09 & 16.78 & 2.76 & 2.21 \\
\hline & Abha & 2.89 & 39.54 & 2.70 & 2.64 \\
\hline & Mindak & 3.26 & 19.64 & 3.68 & 4.66 \\
\hline & Ibalah & 1.22 & 28.85 & 3.29 & 5.12 \\
\hline \multirow[t]{5}{*}{ III C } & Thulth Bani Amer & 3.93 & 17.66 & 6.89 & 9.64 \\
\hline & Tenomah & 4.86 & 19.96 & 8.69 & 12.20 \\
\hline & Alaya & 3.88 & 18.13 & 7.51 & 13.68 \\
\hline & Sir Lasan & 2.63 & 30.82 & 3.23 & 4.08 \\
\hline & Ademah & 1.78 & 9.21 & 1.85 & 5.42 \\
\hline \multirow[t]{2}{*}{ III D } & Khamis & 1.70 & 40.96 & 3.48 & 4.59 \\
\hline & Tajer & 2.67 & 11.83 & 3.09 & 5.81 \\
\hline \multirow[t]{2}{*}{ IV A } & Shafa escarpment & 0.73 & 24.48 & 3.25 & 5.35 \\
\hline & Shafa Bani Sofian & 2.38 & 14.71 & 3.22 & 4.71 \\
\hline \multirow[t]{4}{*}{ IV B } & Mid escarpment & 3.31 & 26.94 & 6.42 & 8.75 \\
\hline & Wadi Daygah & 8.01 & 6.39 & 4.43 & 3.80 \\
\hline & Hema Saysid & 7.88 & 37.89 & 8.09 & 8.41 \\
\hline & Taif & 6.06 & 16.55 & 2.78 & 2.42 \\
\hline \multirow[t]{3}{*}{ IV C } & Sayl Al-Kabir & 6.33 & 25.74 & 7.53 & 6.18 \\
\hline & Turabah & 3.48 & 19.10 & 7.23 & 7.85 \\
\hline & Wadi Turabah & 2.81 & 18.59 & 1.85 & 1.35 \\
\hline \multirow[t]{3}{*}{ V } & Samakh & 5.68 & 11.39 & 6.15 & 8.09 \\
\hline & Heifah & 4.68 & 2.74 & 0.74 & 0.91 \\
\hline & Bishah & 6.48 & 6.55 & 6.47 & 4.57 \\
\hline \multicolumn{6}{|c|}{$\begin{array}{l}{ }^{\mathrm{d}} \mathrm{N}=23, \mathrm{df}=4, \chi^{2}{ }_{0.01}=13.3, \chi^{2}{ }_{005}=9.49, \chi_{01}^{2}=7.78 \\
{ }^{\mathrm{b}} \mathrm{N}=23, \mathrm{df}=5, \chi^{2}=15.1, \chi^{2}{ }_{005}=11.1, \chi^{2}=9.24\end{array}$} \\
\hline
\end{tabular}

Region III at the top of the escarpment shows the highest annual rainfall. Spring is the most likely season for rainfall, while autumn is not favorable in most of the regions in the area of the study.

Region III shows the maximum probability of receiving discrete amounts of rainfall. The probability decreases from $90 \%$ for $100 \mathrm{~mm}$ to $10 \%$ for $600 \mathrm{~mm}$. The rainfall distributions for the study area are generally best described by the normal and the gamma distributions. The exponential distribution is unacceptable.

The interannual variability shows that rainfall distribution over the southwestern region is not uniform. There are many factors affecting its irregularity, such as elevation, topographic configuration and orientation. Rainfall variability in the study area is high, although still lower than variability in other parts of the country (Abdullah et al. 1992). Moreover, region III is characterized by the lowest rainfall variability compared with the other regions in the study area. The analysis of $\left[I_{d v}\right]$ and $\left[I_{d v}\right]_{\mathrm{rel}}$ showed that regions I and $\mathrm{V}$ can be classified as arid, while regions II, III and IV can be classified as semi-arid.

\section{LITERATURE CITED}

Abdullah MA, Afeef MA, Azhari AA (1992) Climatological study over Asir for possible choice of weather modification site. Technical report, King Abdul Aziz University, Jeddah Abdulrazzak MJ, Sorman AU, Onder H, Al-Sari AM (1995) Flood estimation and impact: southwestern region of Saudi Arabia. Final report for project No. AR-10-51, KACST, KSA, Riyadh

Brichambaut GPD, Wallen CC (1963) A study of agroclimatology in semi-arid and arld zones of the near east. WMO technical note no. 56, Geneva

Chow VT (1954) The log-probability law and its engineering applications. Proc Am Soc Civil Eng 80:536-1-536-25

Eltaher $E$ (1992) Drought frequency analysis of annual rainfall series in central and western Sudan. Hydrol Sci J 37: 185-199

Damon RA, Harvey WR (1987) Experimental design, anova and regression. Harper and Row, New York

Haan CT (1979) Statistical methods in hydrology. Iowa State University Press, Ames

Odumodu LO (1983) Rainfall distribution, variability and 

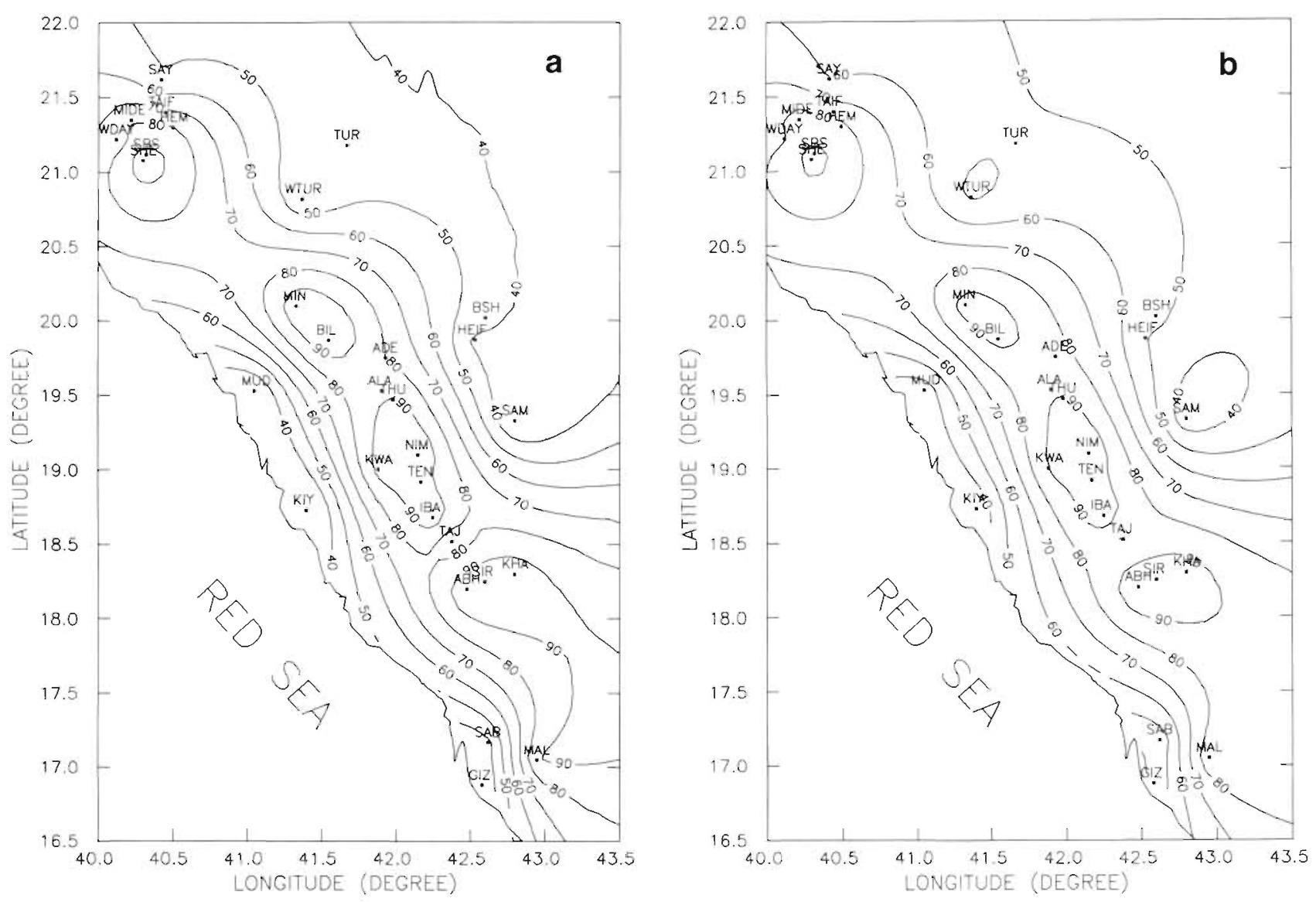

Fig. 12. Probability that rainfall exceeds $100 \mathrm{~mm}$. (a) Gamma distribution; (b) normal distribution

probability in plateau state, Nigeria. J Clim 3:385-393 Panfosky HA (1976) Some applications of statistics to meteorology. University of Pennsylvania, University Park

Rodhe H, Virji H (1976) Trends and periodicities in East Africa rainfall data. Mon Wea Rev 104:307-315

Editorial responsibility: Chris de Freitas, Auckland, New Zealand
Steel RGD, Torrie JH (1980) Principle and procedure of statistics. McGraw-Hill, New York

Waylen PR, Qusesada ME, Caviedes CN (1996) Temporal and spatial variability of annual precupitation in Costa Rica and the southern oscillation. Int $\mathrm{J}$ Climatol 14:173-193

Submitted: February 3, 1997; Accepted: June 19, 1997 Proofs received from author(s): February 25, 1998 